\title{
Trimethylamine Oxide (TMAO): A New Toxic Kid on the Block
}

\section{Saravanan Subramaniam*}

Blood Research Institute, Blood Center of Wisconsin, Milwaukee, USA

Trimethylamine N-oxide (TMAO), a small, organic, oxygenated product of trimethylamine (TMA), belongs to the class of amine oxides [1]. Most of the TMA derived from the metabolism of choline, $\mathrm{L}$-carnitine by bacteria in the gut and is absorbed into the bloodstream. TMA is rapidly oxidized to TMAO by the hepatic enzyme, flavincontaining monooxygenase-3 (FMO3) [2-4]. Systemic concentration of TMAO in normal healthy individuals ranges from $0.5-5 \mu \mathrm{M}[1,5]$. $50 \%$ of the TMAO does not get metabolized and is excreted unchanged within $24 \mathrm{~h}$ through urine, sweat and breath [6-8].

Clinical findings suggest that there is a potential link between the metabolites produced by the gut flora and the risk factors for cardiovascular and other diseases such as kidney failure, thrombosis, atherosclerosis, obesity, diabetes, and cancer [2]. Several studies have reported an association between plasma TMAO and choline levels in patients with heart failure [9-12]. TMAO negatively regulates glucose metabolism which leads to diabetes mellitus [13]. An observational clinical study reveals elevated levels of plasma TMAO were a strong risk marker for diabetes. Diabetic patients with high plasma TMAO levels was a marker of adverse cardiovascular outcomes, such as death (HR 2.7), myocardial infarction (HR 4.0), heart failure (HR 4.6), unstable angina (HR 9.1) and other cardiovascular complications (HR 2.0) [14]. Though the mechanisms behind the risk are undefined, TMAO could be a valuable marker to predict the risk of diabetes and its complications. The contribution of TMAO to the progression of renal dysfunction shows that chronic dietary intake elevates the plasma TMAO levels directly and leads to progressive renal fibrosis and dysfunction [15]. TMAO levels were considerably elevated in ischemic kidney damage triggered by either cold ischemia or transplantation $[16,17]$.

Studies have shown that TMAO activates inflammatory pathways in cells of the vasculature leading to augmented endothelial cell-leukocyte interactions and atherosclerosis. Studies on both in vivo and in vitro cultured human aortic endothelial cells and vascular smooth muscle cells showed that elevated levels of TMAO induce expression of proinflammatory cytokines and adhesion molecules mediated by the NF- $\kappa \mathrm{B}$ signaling pathway [18]. TMAO enhances monocyte activation as well as adhesion by activating endothelial cells to express VCAM-1 [19,20]. Interestingly, recent findings reported that a raised systemic concentration of TMAO $(100 \mu \mathrm{M})$ showed increased platelet hyper reactivity and platelet aggregation in vitro and in vivo. A couple of clinical data indicated that colorectal cancer is positively linked to plasma TMAO levels. Similarly, experimental findings suggested that urinary TMAO could be used as a prognosticator for gastric tumorigenesis [21,22]. In contrast, TMAO also corrects the mutant protein-folding defect and protective from carcinogenesis $[23,24]$.
Since the microbiome is considered to be the source of TMAO, antibiotic treatment should reduce its circulating levels. However, antibiotics are not an ideal treatment since it could have other unwanted consequences, and also chronic treatment may lead to bacteria resistant. Meanwhile, removing TMAO producing bacteria, use of specific bacteria to increase its metabolism has also been attempted [25]. Furthermore, controlled intake of dietary precursors of TMAO is a possible approach. Besides, several pathway inhibitors are reported to reduce the TMA and TMAO levels in plasma (Figure 1). Indeed, people who eat plant-based diet appear to form a negligible amount of TMAO [26]. Our understanding of the diet and microbial metabolites interaction and their influence on human health is at an initial stage. Nevertheless, increasing evidence suggests that a plantbased diet may be beneficial for this interaction in many ways. On the other hand, there is accruing clinical and laboratory-based findings convincing a pathogenic role to TMAO. It is essential to commence studies examining intracellular levels of TMAO in mammals, cellular signaling and also define the effects of TMAO on enzymes and other proteins to establish the role of TMAO in health and disease in humans. Also, comparing the infection models with germ-free mice models could support our understanding of how gut flora influence various diseases.

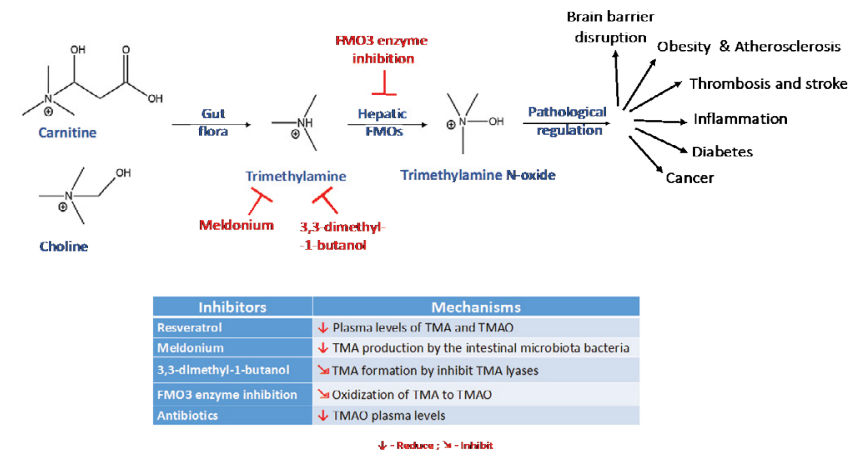

Figure 1: TMAO synthesis, pathological complications, and known inhibitors.

*Corresponding author: Saravanan Subramaniam, Blood Research Institute Blood Center of Wisconsin, Milwaukee, USA, Tel: +1919 260 2381; E-mail: saravanan.subramaniam@bcw.edu

Received January 25, 2018; Accepted January 29, 2018; Published February 05, 2018

Citation: Subramaniam S (2018) Trimethylamine Oxide (TMAO): A New Toxic Kid on the Block. J Biomol Res Ther 7: e159. doi:10.4172/2167-7956.1000e159

Copyright: (c) 2018 Subramaniam S. This is an open-access article distributed under the terms of the Creative Commons Attribution License, which permits unrestricted use, distribution, and reproduction in any medium, provided the original author and source are credited. 


\section{References}

1. Ufnal M, Zadlo A, Ostaszewski R (2015) TMAO: A small molecule of great expectations. Nutrition 31: 1317-23.

2. Subramaniam S, Fletcher C (2017) Trimethylamine N-oxide: breathe new life. $\mathrm{Br} J$ Pharmacol.

3. Bennett BJ, de Aguiar VTQ, Wang Z, Shih DM, Meng Y, et al. (2013) Trimethylamine-N-oxide, a metabolite associated with atherosclerosis, exhibits complex genetic and dietary regulation. Cell Metab 17: 49-60.

4. Koeth RA, Levison BS, Culley MK, Buffa JA, Wang Z, et al. (2014) gammaButyrobetaine is a proatherogenic intermediate in gut microbial metabolism of L-carnitine to TMAO. Cell Metab 20: 799-812.

5. Wang Z, Klipfell E, Bennett BJ, Koeth R, Levison BS, et al. (2011) Gut flora metabolism of phosphatidylcholine promotes cardiovascular disease. Nature 472: 57-63.

6. Ayesh R, Mitchell SC, Zhang A, Smith RL (1993) The fish odour syndrome: biochemical, familial, and clinical aspects. BMJ 307: 655-7.

7. Smith JL, Wishnok JS, Deen WM (1994) Metabolism and excretion of methylamines in rats. Toxicol Appl Pharmacol 125: 296-308.

8. Zhang AQ, Mitchell SC, Smith RL (1999) Dietary precursors of trimethylamine in man: a pilot study. Food Chem Toxicol 37: 515-20.

9. Tang WH, Wang Z, Fan Y, Levison B, Hazen JE, et al. (2014) Prognostic value of elevated levels of intestinal microbe-generated metabolite trimethylamine$\mathrm{N}$-oxide in patients with heart failure: refining the gut hypothesis. J Am Coll Cardiol 64: 1908-14.

10. Troseid M, Ueland T, Hov JR, Svardal A, Gregersen I, et al. (2015) Microbiotadependent metabolite trimethylamine- $\mathrm{N}$-oxide is associated with disease severity and survival of patients with chronic heart failure. J Intern Med 277: 717-26.

11. Tang WH, Wang Z, Shrestha K, Borowski AG, Wu Y, et al. (2015) Intestina microbiota-dependent phosphatidylcholine metabolites, diastolic dysfunction, and adverse clinical outcomes in chronic systolic heart failure. J Card Fail 21 $91-6$.

12. Troseid M, Hov JR, Nestvold TK, Thoresen H, Berge RK, et al. (2016) Major Increase in Microbiota-Dependent Proatherogenic Metabolite TMAO One Year After Bariatric Surgery. Metab Syndr Relat Disord 14: 197-201.

13. Randrianarisoa E, Lehn-Stefan A, Wang X, Hoene M, Peter A, et al. (2016) Relationship of Serum Trimethylamine N-Oxide (TMAO) Levels with early Atherosclerosis in Humans. Sci Rep 6: 26745.
14. Lever M, George PM, Slow S, Bellamy D, Young JM, et al. (2014) Betaine and Trimethylamine-N-Oxide as Predictors of Cardiovascular Outcomes Show Different Patterns in Diabetes Mellitus: An Observational Study. PLoS One 9: e114969.

15. Tang WH, Wang Z, Kennedy DJ, Wu Y, Buffa JA, et al. (2015) Gut microbiotadependent trimethylamine $\mathrm{N}$-oxide (TMAO) pathway contributes to both development of renal insufficiency and mortality risk in chronic kidney disease. Circ Res 116: 448-55.

16. Hauet T, Baumert H, Gibelin H, Godart C, Carretier M, et al. (2000) Citrate acetate and renal medullary osmolyte excretion in urine as predictor of renal changes after cold ischaemia and transplantation. Clin Chem Lab Med. 38 . 1093-8.

17. Doucet C, Dutheil D, Petit I, Zhang K, Eugene M, et al. (2004) Influence of colloid, preservation medium and trimetazidine on renal medulla injury. Biochim Biophys Acta 1673: 105-114.

18. Seldin MM, Meng Y, Qi H, Zhu W, Wang Z, et al. (2016) Trimethylamine N-Oxide Promotes Vascular Inflammation Through Signaling of Mitogen-Activated Protein Kinase and Nuclear Factor- KB. J Am Heart Assoc. 5: e002767.

19. Ma G, Pan B, Chen Y, Guo C, Zhao M, et al. (2017) Trimethylamine N-oxide in atherogenesis: impairing endothelial self-repair capacity and enhancing monocyte adhesion. Biosci Rep 37: BSR20160244.

20. Haissman JM, Haugaard AK, Ostrowski SR, Berge RK, Hov JR, et al. (2017) Microbiota-dependent metabolite and cardiovascular disease marker trimethylamine-N-oxide (TMAO) is associated with monocyte activation but not platelet function in untreated HIV infection. BMC Infect Dis. 17: 445.

21. Kim KB, Yang JY, Kwack SJ, Park KL, Kim HS, et al. (2010) Toxicometabolomics of urinary biomarkers for human gastric cancer in a mouse model. $\mathrm{J}$ Toxicol Environ Health A 73: 1420-30.

22. Bae S, Ulrich CM, Neuhouser ML, Malysheva O, Bailey LB, et al. (2014) Plasma choline metabolites and colorectal cancer risk in the Women's Health Initiative Observational Study. Cancer Res 74: 7442-52.

23. Lunn JC, Kuhnle G, Mai V, Frankenfeld C, Shuker DE, et al. (2007) The effect of haem in red and processed meat on the endogenous formation of $\mathrm{N}$-nitroso compounds in the upper gastrointestinal tract. Carcinogenesis 28: 685-90.

24. Georgescauld F, Mocan I, Lacombe ML, Lascu I (2009) Rescue of the neuroblastoma mutant of the human nucleoside diphosphate kinase $\mathrm{A} / \mathrm{nm} 23-\mathrm{H} 1$ by the natural osmolyte trimethylamine-N-oxide. FEBS Lett 583: 820-4.

25. Velasquez MT, Ramezani A, Manal A, Raj DS (2016) Trimethylamine N-Oxide: The Good, the Bad and the Unknown. Toxins (Basel) 8: 326

26. Campbell T (2017) A plant-based diet and stroke. J Geriatr Cardiol 14: 321-6. 